\title{
Pregnancy outcome of isolated oligohydramnios in uncomplicated term pregnancies: an observational comparative study
}

\author{
Gisi Sebastian$^{1 *}$, K. P. Shiyas ${ }^{2}$
}

\begin{abstract}
${ }^{1}$ Department of Obstetrics and Gynaecology, ${ }^{2}$ Department of Paediatrics, Al Azhar Medical College and Super Speciality Hospital, Thodupuzha, Idukki, Kerala, India
\end{abstract}

Received: 22 January 2022

Revised: 07 February 2022

Accepted: 07 February 2022

*Correspondence:

Dr. Gisi Sebastian,

E-mail: gisirahul@gmail.com

Copyright: () the author(s), publisher and licensee Medip Academy. This is an open-access article distributed under the terms of the Creative Commons Attribution Non-Commercial License, which permits unrestricted non-commercial use, distribution, and reproduction in any medium, provided the original work is properly cited.

\section{ABSTRACT}

Background: Oligohydramnios and its outcome is a relevant issue related to mother and fetus. Purpose of this study is to establish the obstetric and perinatal outcome in pregnancy associated with 'isolated oligohydramnios as compared to women with normal liquor.

Methods: This is an observational comparative study done at Al Azhar Medical College, Thodupuzha, Kerala, India on 50 pregnant women of 37 weeks of gestation or more and diagnosed to have oligohydramnios without any high-risk factors. Age, parity, gestational age matched patients without any high-risk factors and AFI $>5 \mathrm{~cm}$ attending the OPD /ward were taken as controls. In each group there were 25 subjects. After getting informed consent those who fulfilled inclusion criteria were followed through the delivery and immediate neonatal outcome were assessed. Parameters like age, parity, amniotic fluid volume, gestational age at delivery, mode of onset of labor, indication of induction, methods of induction, need for augmentation of labor, CTG patterns, color of liquor, mode of delivery, indications of caesarean section., distribution of APGAR score were analyzed.

Results: There were significant difference in maternal outcomes in patients with isolated oligohydramnios in the form of increased rates of induction of labor, augmentation of labor, meconium-stained liquor, non-reassuring fetal heart pattern, caesarean section rates without any significant effects on neonatal outcome.

Conclusions: Isolated oligohydramnios has increased rate of induction of labor, meconium-stained liquor, CTG abnormalities and caesarean section rates without significant increase in neonatal morbidity and mortality.

Keywords: Isolated oligohydramnios, Maternal outcome, Meconium-stained liquor

\section{INTRODUCTION}

Amniotic fluid is very important for growth of fetus in sterile environment, avoidance of external injury and reduction of impact of uterine contractions. Oligohydramnios is a condition where amniotic fluid volume is very low and it has been associated with poor pregnancy outcomes. It can cause increased risk of intrauterine growth restriction, meconium aspiration syndrome, severe birth asphyxia, low APGAR score and maternal morbidity in the form of increased risk induction of labor, operative interventions etc. ${ }^{1,2}$ Thus evaluation of amniotic fluid has become an integral part of antenatal fetal assessment.

According to some studies oligohydramnios has significant impact on maternal and neonatal outcome while some others observed that isolated oligohydramnios had no adverse effect on perinatal outcome. 5 The incidence of oligohydramnios with general reporting rate is 1 and 3 percent. Oligohydramnios per se does not lead to maternal complications but its underlying cause may. Irrespective of the cause, mother is at risk of a caesarean 
delivery for fetal distress secondary to growth restriction, malformation or umbilical cord compression. ${ }^{3-5}$

Chauhan and associates performed a meta-analysis of 18 studies in which they found that oligohydramnios has increased risk of caesarean section for fetal distress and increased risk of low Apgar score. ${ }^{6}$ Baron et al reported that cord compression during labor is very common in oligohydramnios and it can cause variable decelerations and increased rate of caesarean section. ${ }^{7}$ Divon et al studied 638 women with post term pregnancy in labor and found that only those with AFI $<5$ had fetal heart rate decelerations and meconium stained liquor. ${ }^{8}$

Magnam et al found that those with AFI of less than 5 had similar outcomes to those with normal AFI and concluded that an AFI less than $5 \mathrm{~cm}$ is not an indication for delivery. ${ }^{9}$ Similarly, Rainford et al and Zhang et al reported that isolated oligohydramnios were not associated with adverse pregnancy outcome. ${ }^{2,10}$ Thus there is increasing evidence that patients with isolated oligohydramnios with a normally growing fetus, good fetal movement and an unfavourable cervix may be candidates for observations and therapeutic interventions like oral /intravenous administration of water /crystalloids or both to increase the amniotic fluid level can be tried. ${ }^{11}$

The management of isolated oligohydramnios is controversial. Some authors prefer to induce labor as development of oligohydramnios can cause chronic hypoxia. However, some studies show that pregnancy outcome is not affected by inductions in otherwise normal pregnancy, because most of the morbidity occurs during Intrapartum period. But if severe oligohydramnios is present delivery can be considered.

\section{METHODS}

It is an observational comparative study carried out at $\mathrm{Al}$ Azhar Medical College, Thodupuzha, Kerala, India from march 2020 to march 2021. Study population comprised 25 antenatal women with isolated oligohydramnios and 25 antenatal women with normal AFI.

\section{Inclusion criteria}

Singleton pregnancies, $\geq 37$ weeks of gestation and Intact membranes.

\section{Exclusion criteria}

Previous cesarean section, rupture of membrane, medical disorders like preeclampsia, diabetes etc., Malpresentation, IUGR, multiple gestation and anomalous fetus.

Sampling procedure was continuous and 25 pregnant women $>37$ weeks with isolated oligohydramnios and 25 pregnant women $>37$ weeks with normal AFI were recruited for the study. This study was started with human ethical committee approval. During the time period informed consent was obtained from all the antenatal women who fulfilled the inclusion and exclusion criteria. They were divided into two groups. One group with isolated oligohydramnios and other with normal AFI. In both groups' 25 pregnant women each and following parameters were assessed.

\section{Parameters to assess pregnancy outcome}

Age of patient, gravidity, amniotic fluid volume, gestational age at delivery, mode of onset of labor, indication of induction of labor, methods of induction of labor, need for augmentation of labor, CTG (reassuring /non reassuring), color of liquor, mode of delivery, indications of cesarean section and APGAR score

\section{Data collection}

All data were entered into excel (MS excel 2011). Privacy and confidentiality was maintained. All patient identifiable numbers and information's was stripped and replaced by anonymous numbers.

\section{Statistical analysis}

Statistical analysis was performed by using IBM Statistical package for social sciences (SPSS) statistics software (version 24; IBM, New York, USA). The comparisons of counting data were evaluated using chi-square test. A pvalue of less than 0.05 was considered as significant.

\section{RESULTS}

During the study period total number of patients was 50, in those 25 patients with isolated oligohydramnios and 25 patients with normal AFI. In that majority of the patients were around 20-25 years of age. (Table 1). In our observation primigravida were $76 \%$ in study group and $80 \%$ in control group respectively. Multigravida was only $24 \%$ in study group and $20 \%$ in control group respectively. So in our observation majority of patients were primigravida in both groups. (Table 1)

\section{Table 1: Age.}

\begin{tabular}{|c|c|c|c|}
\hline Age (years) & $\begin{array}{l}\text { Study } \\
\text { group } \\
\text { n (\%) }\end{array}$ & $\begin{array}{l}\text { Control } \\
\text { group } \\
\text { n }(\%)\end{array}$ & $\begin{array}{l}\mathbf{P} \\
\text { value }\end{array}$ \\
\hline $20-25$ & 15 & 13 & \multirow{3}{*}{0.57} \\
\hline $26-30$ & 10 & 12 & \\
\hline Total & $25(100)$ & $25(100)$ & \\
\hline \multicolumn{4}{|l|}{ Gravida } \\
\hline 1 & 19 & 20 & \multirow{4}{*}{0.919} \\
\hline 2 & 4 & 3 & \\
\hline 3 & 2 & 2 & \\
\hline Total & $25(100)$ & $25(100)$ & \\
\hline
\end{tabular}


In our study group around $48 \%$ patients had AFI $4.1-5 \mathrm{~cm}$, $38 \%$ had $3.1-4 \mathrm{~cm}$ and $20 \%$ had $<3 \mathrm{~cm}$ whereas in control group $84 \%$ had normal AFI and $8 \%$ had $5-9 \mathrm{~cm}$. (Table 2) $48 \%$ of both groups delivered between $39-39+6$ weeks, $28 \%$ women delivered between $40-41$ weeks, and $24 \%$ women delivered between 37-38+6 weeks respectively. This was not statistically significant. (Table 3)

Table 2: Distribution of AFI in study group and control group.

\begin{tabular}{|lll|}
\hline $\begin{array}{l}\text { AFI }(\mathrm{CM}) \\
\text { study group }\end{array}$ & Number & Percentage \\
\hline$<\mathbf{3}$ & 5 & 20 \\
\hline $\mathbf{3 . 1 - 4}$ & 8 & 32 \\
\hline $\mathbf{4 . 1 - 5}$ & 12 & 48 \\
\hline Total & 25 & 100 \\
\hline AFI $(\mathbf{C M})$ & control group & \\
\hline $\mathbf{5 - 7}$ & 2 & 8 \\
\hline $\mathbf{7 . 1 - 9}$ & 2 & 8 \\
\hline $\mathbf{9 . 1 - 1 1}$ & 10 & 40 \\
\hline $\mathbf{> 1 1}$ & 11 & 44 \\
\hline Total & 25 & 100 \\
\hline
\end{tabular}

Table 3: Gestational age at delivery.

\begin{tabular}{|c|c|c|c|}
\hline $\begin{array}{l}\text { Gestational } \\
\text { age }\end{array}$ & $\begin{array}{l}\text { Study } \\
\text { group } \\
\text { n (\%) }\end{array}$ & $\begin{array}{l}\text { Control } \\
\text { group } \\
\text { n }(\%)\end{array}$ & $P$ value \\
\hline $37-38+6$ & 6 & 6 & \multirow{4}{*}{1} \\
\hline $39-39+6$ & 12 & 12 & \\
\hline $40-41$ & 7 & 7 & \\
\hline Total & $25(100)$ & $25(100)$ & \\
\hline
\end{tabular}

Table 4: Mode of onset of labour.

\begin{tabular}{|c|c|c|c|}
\hline Labor onset & $\begin{array}{l}\text { Study } \\
\text { group } \\
\text { n }(\%)\end{array}$ & $\begin{array}{l}\text { Control } \\
\text { group } \\
\text { n }(\%)\end{array}$ & $P$ value \\
\hline Spontaneous & 10 & 22 & \multirow{3}{*}{$<0.001$} \\
\hline Induced & 15 & 3 & \\
\hline Total & $25(100)$ & $25(100)$ & \\
\hline
\end{tabular}

In this study, rate of induction was $60 \%$ in study group and $12 \%$ in control group. This was statistically significant. $88 \%$ in control group had spontaneous onset of labor, whereas only $40 \%$ of study group had spontaneous labor. This shows that rate of induction with isolated oligohydramnios was more compared to control group (Table 4). In that induced patients $58 \%$ had oligohydramnios as the indication of induction. This was statistically significant. (Table 5) Out of 15 patients in the study group who had labor induction $11(73.3 \%)$ were induced with Foley's alone .and only 4 (26.6\%) needed multiple inducing agents. (Table 5). In case of augmentation of labor more women in the study group required oxytocin augmentation compared to the control group. This was statistically significant. (Table 5)
Table 5: Indication of induction, methods of induction, augmentation of labor.

\begin{tabular}{|c|c|c|c|}
\hline Indication & $\begin{array}{l}\text { Study } \\
\text { group } \\
\text { n }(\%)\end{array}$ & $\begin{array}{l}\text { Control } \\
\text { group } \\
\text { n }(\%)\end{array}$ & $P$ value \\
\hline Not induced & 10 & 22 & \multirow{4}{*}{0.00061} \\
\hline Oligohydramnios & 13 & 1 & \\
\hline Post dates & 2 & 2 & \\
\hline Total & $25(100)$ & $25(100)$ & \\
\hline \multicolumn{4}{|l|}{ Methods } \\
\hline Not induced & 10 & 22 & \multirow{5}{*}{0.0036} \\
\hline Foley's & 11 & 1 & \\
\hline Foley's+PGE1 & 2 & 1 & \\
\hline Foley's+2PGE1 & 2 & 1 & \\
\hline Total & $25(100)$ & $25(100)$ & \\
\hline \multicolumn{4}{|c|}{ Oxytocin augmentation } \\
\hline Yes & 23 & 3 & \multirow{3}{*}{$<0.001$} \\
\hline No & 2 & 22 & \\
\hline Total & $25(100)$ & $25(100)$ & \\
\hline
\end{tabular}

Table 6: Comparison of intrapartum CTG between the groups.

\begin{tabular}{|c|c|c|c|}
\hline & $\begin{array}{l}\text { Study } \\
\text { group } \\
\text { n }(\%)\end{array}$ & $\begin{array}{l}\text { Control } \\
\text { group } \\
\text { n }(\%)\end{array}$ & $P$ value \\
\hline $\begin{array}{l}\text { Non } \\
\text { reassuring }\end{array}$ & 17 & 2 & \multirow{3}{*}{$<0.001$} \\
\hline Reassuring & 8 & 23 & \\
\hline Total & $25(100)$ & $25(100)$ & \\
\hline
\end{tabular}

Table 7: Colour of liquor.

\begin{tabular}{|c|c|c|c|}
\hline Liquor & $\begin{array}{l}\text { Study } \\
\text { group } \\
\text { n }(\%)\end{array}$ & $\begin{array}{l}\text { Control } \\
\text { group } \\
\text { n ( } \%)\end{array}$ & $P$ value \\
\hline Clear & 11 & 21 & \multirow{5}{*}{$<0.001$} \\
\hline Thin MSL & 2 & 1 & \\
\hline $\begin{array}{l}\text { Moderate } \\
\text { MSL }\end{array}$ & 10 & 2 & \\
\hline Thick MSL & 2 & 1 & \\
\hline Total & $25(100)$ & $25(100)$ & \\
\hline
\end{tabular}

In our study Out of 25 patients, $68 \%$ had non-reassuring fetal heart rate in the study group in comparison to $8 \%$ in control group. This was statistically significant. This shows that isolated oligohydramnios has more risk of non reassuring fetal heart rate pattern during Intrapartum period which may increase the need for operative intervention and poor neonatal outcome. (Table 6, 8) In study group $73 \%$ of patients, the indication of cesarean section was NRFHR (Table 9). But in this study $56 \%$ of patients in study group had meconium stained liquor whereas only $16 \%$ had meconium stained liquor in control group. This was statistically significant. Out of $56 \%$ patients in study group who had meconium staining, $71.4 \%$ had moderate MSL and $14.3 \%$ had thick MSL. But 
only those who had thick MSL (13\%) in study group needed cesarean section for MSL. (Table 7)

Table 8: Mode of delivery.

\begin{tabular}{|c|c|c|c|}
\hline $\begin{array}{l}\text { Mode of } \\
\text { delivery }\end{array}$ & $\begin{array}{l}\text { Study } \\
\text { group } \\
\text { n }(\%)\end{array}$ & $\begin{array}{l}\text { Control } \\
\text { group } \\
\text { n }(\%)\end{array}$ & $P$ value \\
\hline $\begin{array}{l}\text { Spontaneous } \\
\text { vaginal } \\
\text { delivery }\end{array}$ & 10 & 22 & \multirow{3}{*}{$<0.001$} \\
\hline $\begin{array}{l}\text { Cesarean } \\
\text { section }\end{array}$ & 15 & 3 & \\
\hline Total & $25(100)$ & $25(100)$ & \\
\hline
\end{tabular}

Table 9: Indications of caesarean section.

\begin{tabular}{|c|c|c|c|}
\hline Indication & $\begin{array}{l}\text { Study } \\
\text { group } \\
\text { n }(\%)\end{array}$ & $\begin{array}{l}\text { Control } \\
\text { group } \\
\text { n }(\%)\end{array}$ & P value \\
\hline $\begin{array}{l}\text { MSL in early } \\
\text { labor }\end{array}$ & 2 & 1 & \multirow{4}{*}{0.406} \\
\hline Fetal distress & 2 & 1 & \\
\hline NRFHR & 11 & 1 & \\
\hline Total & 15 & 3 & \\
\hline
\end{tabular}

Table 10: Distribution of APGAR score.

\begin{tabular}{|c|c|c|c|}
\hline $\begin{array}{l}\text { APGAR } \\
\text { score }\end{array}$ & $\begin{array}{l}\text { Study } \\
\text { group } \\
\text { n }(\%)\end{array}$ & $\begin{array}{l}\text { Control } \\
\text { group } \\
\text { n }(\%)\end{array}$ & P value \\
\hline$<7$ & 2 & 1 & \multirow{3}{*}{0.55} \\
\hline$>7$ & 23 & 24 & \\
\hline Total & $25(100)$ & $25(100)$ & \\
\hline
\end{tabular}

In our observation, $92 \%$ babies in the study group had an Apgar score of $>7$ at 5 min and $96 \%$ of babies in control group had an Apgar score of $>7$ which was not significant. The table shows only 3 babies had Apgar score $<7$ in that 2 babies had mild grunting which was self-limiting doesn't needed NICU admission and 1 baby had congenital heart disease (tricuspid artesia) detected after delivery. The difference was not significant. (Table 10)

\section{DISCUSSION}

The present study was conducted in the department of obstetrics and gynecology, Al Azhar Medical College, Thodupuzha. This study was done to evaluate the pregnancy outcome in isolated oligohydramnios in uncomplicated term pregnancy compared with those patients with normal AFI. A detailed history was taken and physical examination was done. They were investigated appropriately and managed according to hospital protocol for the condition.

Majority of the women recruited in this study belong to the age group of 20-25years. By Kreiser et al mentioned similar results in his study. The younger age group of women in our study was because our hospital population who came for delivery was mostly belonged to younger age group. ${ }^{12}$

Majority of the women in both groups were primigravida. Other authors also found no significant difference between the groups when parity was compared. ${ }^{12,13}$ In the study by Casey et al, $40 \%$ in study group and $37 \%$ in control group were primigravida. ${ }^{13}$

In this study majority of the patients delivered between 38$39+6$ weeks. Similar results were found by Krieser et al in this study $48 \%$ women in each group delivered between $38-39+6$ weeks, $28 \%$ women delivered between 40 and 41 weeks and $24 \%$ delivered between $37-37+6$ weeks. ${ }^{12}$ Among 25 women in study group $48 \%$ had AFI between $4.1-5 \mathrm{~cm}$ and $44 \%$ in the control group had AFI $>11$.

In this study, the rate of induction of labor was significantly more $(60 \%)$ in the study group compared to the control group. Similarly, Casey et al and Rainford et al stated that induction of labor was significantly increased with oligohydramnios compared to control group. ${ }^{13,14}$ But other studies did not show any difference in rate of induction of labor between the oligohydramnios and borderline AFI groups. ${ }^{12}$

$73 \%$ women with isolated oligohydramnios were planned for induction of labor. In that pre induction cervical ripening was done with intracervical Foley's catheter and/or intracervical PGE1. Among these 2 went into labor without further requirement of any augmentation.

In this study there was statistically significant difference in the Intrapartum fetal heart rate abnormalities between the two groups. $68 \%$ of women had non- reassuring CTG in the study group in comparison to $8 \%$ in control group. Casey et al and Wenstrom et al reported that FHR abnormalities during labor were increased in study group, but their study included high risk patients too. FHR decelerations detected were due to cord compression. ${ }^{15,16}$ Divon et al found that FHR abnormalities were significantly higher when the AFI fell below $5 \mathrm{~cm} .^{6}$

in this study there was statistically significant difference in the Intrapartum meconium staining of liquor between 2 groups; $56 \%$ of patients in study group had MSL whereas only $16 \%$ had MSL in control group. Phelan et al and Divon et al found that MSL was significantly higher when the AFI fell below $5 \mathrm{~cm} \cdot{ }^{6,17}$ But Rainford et al found that women with normal AFI had significantly higher rate of MSL than those with low AFI. ${ }^{14}$ Casey et al also reported that MSL was identified less often in pregnancies complicated by oligohydramnios compared to control group. ${ }^{13}$

The present study showed significant difference between the groups when the number of operative deliveries in each group was compared; $60 \%$ had caesarean section in study group in comparison to control group which was only 
$12 \%$. The rate caesarean section is high when compared to our hospital caesarean section rate of $30-40 \%$. Non reassuring fetal heart rate, fetal distress, MSL in early labor was the most common indications for caesarean deliveries. Similarly, Chauhan et al showed that relative risk for caesarean delivery for fetal distress associated with ante partum AFI $<5 \mathrm{~cm} .{ }^{6}$ Ahmed et al observed that rate of induction of labor and caesarean delivery were significantly more in isolated oligohydramnios group compared to women having normal AFI. ${ }^{18}$ But in this study the increase in caesarean delivery rate was not truly due to higher rate of fetal distress but presumably due to higher rate of labor induction, thereby increasing the maternal morbidity. It is well known fact that induced labor compared to spontaneous labor results in caesarean section regardless of parity and condition of cervix. ${ }^{19}$

Increase in incidence of Apgar score <3, admission to ICU, respiratory distress syndrome and meconium aspiration syndrome in pregnancies with $\mathrm{AFI}<5 \mathrm{~cm}$ was recorded by Casey et al but in our study only 2 babies in study group and 1 baby in control group had APGAR $<7$ which was self-limiting. ${ }^{2}$ No babies needed NICU admission.

This study showed significant increase in maternal morbidity in the form of labor induction and caesarean deliveries. MSL and non-reassuring fetal heart rate pattern were also increased but without any increase in perinatal mortality.

\section{Limitation}

It was a hospital-based study; the figures are not strictly representative of the whole population. The amniotic fluid level was measured by different personnel. This could have resulted in inter observer variation.

\section{CONCLUSION}

This study may be concluded that in comparison to pregnant women with normal AFI, in those with isolated oligohydramnios- there were significantly increased rates of induction of labor and operative delivery, there were significantly increased rates of meconium-stained liquor and non-reassuring fetal heart rate pattern but there were no significant effects on neonatal outcome in the form of neonatal mortality or major morbidity.

Funding: No funding sources

Conflict of interest: None declared

Ethical approval: The study was approved by the Institutional Ethics Committee

\section{REFERENCES}

1. Sultana S, Khan MN, Akhtar KA, Aslam M. Low amniotic fluid index in high-risk pregnancy and poor Apgar score at birth. J Coll Physicians Surg Pak. 2008;18(10):630-4.
2. Rainford M, Adair R, Scialli AR, Ghidini A, Spong CY. Amniotic fluid index in the uncomplicated term pregnancy: Prediction of outcome. J Reprod Med. 2001;46(6):589-92.

3. Manning FA, Hill LM, Platt LD. Qualitative amniotic fluid volume determination by ultrasound; antepartum detection of intrauterine growth retardation . Am J Obstet Gynecol. 1981;139(3):254-8.

4. Crowley P, O'Herlihy C, Boylan P. The value of ultrasound measurement of amniotic fluid volume in the management of prolonged pregnancies. $\mathrm{Br} \mathrm{J}$ Obstet Gynaecol. 1984;91:444.

5. Moberg LJ, Garite TJ, Freeman RK. Fetal heart rate patterns and fetal distress in patients with preterm premature rupture of membranes. Obstet Gynecol. 1984;64:60-4.

6. Chauhan SP, Sanderson M, Hendrix NW, Magnan EF, Devoe LD. Perinatal outcome and amniotic fluid index in the antepartum and Intrapartum periods: A meta-analysis. Am J Obstet Gynecol. 1999;181:1473.

7. Baron C, Morgan MA, Garite TJ. The impact of amniotic fluid volume assessed intrapartum on perinatal outcome. Am J Obstet Gynecol. 1995; 173:167.

8. Divon MY, Marks AD, Henderson CE. Longitudinal measurement of amniotic fluid index in postterm pregnancies and its association with fetal outcome. Am J Obstet Gynecol. 1995;172:142.

9. MagnanEF, Chauhan SP, Barrilleaux PS, Whitworth NS, Martin JN. Amniotic fluid index and single deepest pocket: Weak indicators of abnormal amniotic volumes. Obstet Gynecol. 2000;96:737.

10. Zang J, Troendle J, Meikle S, Klebanoff MA, Rayburn WF. Isolated oligohydramnios is not associated with adverse perinatal outcomes. Br J Obstet Gynecol. 2004;111:220.

11. Gilbert WM. Amniotic fluid disorders. In: Gabbe S, Niebyl JR,Simpson JL , editors. Obstetrics, normal and problem pregnancies.5th ed. Philadelphia: Elsevier. 2007;834-45.

12. Kreiser D, EI-Sayed YY, Sorem KA, Chitkara U, Holbrook RH, Druzin ML. Decreased amniotic fluid index in low-risk pregnancy. $\mathbf{J}$ Reprod Med. 2001;46:743.

13. Casey BM, Intire DD, Bloom SL, Lucas MJ, Santos $\mathrm{R}$, Twickler DM, et al. "Pregnancy outcome after antepartum diagnosis of oligohydramnios at or beyond 34 weeks of gestation". AmJ Obstet Gynecol. 2000;182:909.

14. Rainford M, Adair R, Scialli AR, Ghidini A, Spong CY. Amniotic fluid index in the uncomplicated term pregnancy.Prediction of outcome. J Reprod Med. 2001;46:589.

15. Strong TH, Hetzler G, Sarno AP, Paul RH. Prophylactic Intrapartum amnioinfusion: a randomized clinical trial. Am J Obstet Gynecol.1990;162:1370-5.

16. Wenstrom KD, Parson MT. The prevention of meconium aspiration in labor using amnioinfusion. Obstet Gynecol. 1989;73:647-51. 
17. Phelan JP, Smith CV, Broussard P, Small M. Amniotic fluid volume assessment using the fourquadrant technique in the pregnancy at 36-42 weeks gestation J Reprod Med. 1987;32:540.

18. Ahmad H, Munim S. Isolated oligohydramnios is not an indicator for adverse perinatal outcome. JPMA. 2009;56:691.

19. Locatelli A, Zaqarella L, Toso L, Assi F, Ghidini A, Biffi A. Serial assessment of AFI in uncomplicated term pregnancies: Prognostic value of amniotic fluid reduction. J Maternal Fetal Neonatal Med. 2004;15:233-6.

Cite this article as: Sebastian G, Shiyas KP.

Pregnancy outcome of isolated oligohydramnios in uncomplicated term pregnancies: an observational comparative study. Int J Reprod Contracept Obstet Gynecol 2022;11:871-6. 